\title{
Drequency of NRAS Gene Mutation in Wild Type KRAS and BRAF Colorectal Cancers; a Single Center Study
}

\author{
Hooria Momenzadeh ${ }^{1}$, Mitra Mirzai ${ }^{1}, Z_{\text {Zahra Jowkar }}{ }^{1}$, Bita Geramizadeh ${ }^{1,2, *}$
}

1. Department of Pathology, Shiraz University of Medical Sciences, Shiraz, Iran

2. Transplant Research Center, Shiraz University of Medical Sciences, Shiraz, Iran

\section{* Corresponding Author:}

Bita Geramizadeh, MD

Department of Pathology, Transplant Research Center, Shiraz University of Medical Sciences, Shiraz, Iran Telefax: + 987136473238

Email: geramib@gmail.com

Received: 09 Sep. 2017

Accepted: 01 Dec. 2017

\section{ABSTRACT}

\section{BACKGROUND}

Incidence of colorectal cancer is increasing in countries such as Iran. Molecular biomarkers play very important role in the diagnosis, treatment, and prognosis of this cancer. Mutation in the RAS family (including KRAS and NRAS) is one of these important molecular biomarkers, which should be tested before starting treatment with anti-EGRF (Epidermal growth factor) drugs.

Objectives: There has been very few reports about the frequency of NRAS mutation from Iran and no study from south of the country. In this article we will describe our experience about the frequency of NRAS mutation in colorectal cancers from the largest referral center in the south of Iran.

\section{METHODS}

During 5 years (2011-2015), we had 52 cases of colorectal cancers with wild type KRAS and BRAF in the hospitals affiliated to Shiraz University of Medical Sciences with enough tissue for molecular studies. NRAS mutation analysis was performed on paraffin embedded formalin fixed tissue of these cases by polymerase chain reaction (PCR)-sequencing method.

\section{RESULTS}

Among these 52 cases of colorectal cancer with wild type KRAS and BRAF, there has been $3(5.7 \%)$ cases with mutant NRAS. One of the mutations has been in codon 12 and two in codon 61. No mutation in codon 13 was found. All the three cases were women with stage IV and well differentiated histomorphology.

\section{CONCLUSION}

Our results showed that frequency of NRAS mutation in colorectal cancer is rare, which is very close to other studies from different geographic areas of the world.

\section{KEYWORDS}

Gene mutation, Colorectal cancers, Molecular biomarkers

Please cite this paper as:

Momenzadeh H, Mirzai M, Jowkar Z, Geramizadeh B. Frequency of NRAS Gene Mutation in Wild Type KRAS and BRAF Colorectal Cancers; a Single Center Study. Middle East J Dig Dis 2018;10:18-23. doi: 10.15171/mejdd.2017.85.

\section{INTRODUCTION}

Colorectal cancer is the fourth common cancer in men and the third common in women. ${ }^{1,2}$ In eastern countries such as Iran, its incidence has significantly increased during the last few years. ${ }^{3}$ Tumor genotyping is rapidly being integrated into routine clinical care to define the most appropriate targeted therapy., ${ }^{3,4}$ One of the most important molecular biomarkers of the human cancers (including colorectal adenocarcinoma) are the RAS family members (KRAS, NRAS, and HRAS), which are frequently found in their mutated, oncogenic forms in hu- 


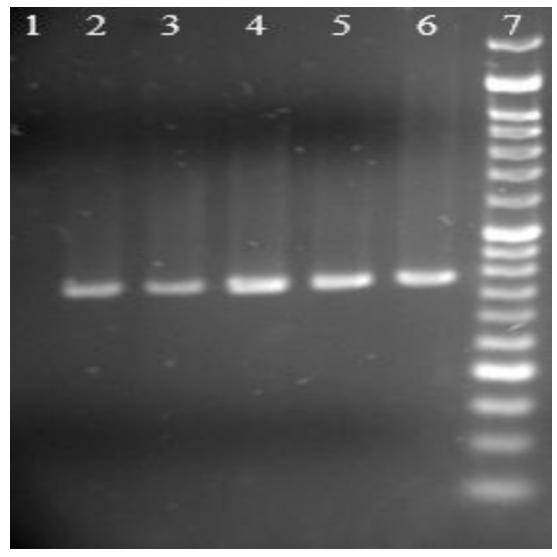

1: Negative control 2, 3, 4, 5, and 6: Patients 7: Ladder

Fig.1: NRAS, codon 12, gel electrophoresis

man tumors. ${ }^{3,4}$ Activating mutations in the RAS genes occur in approximately $20 \%$ of all human cancers, mainly in codons 12,13 , or $61 .^{5-7}$ Among the RAS family, mutations in KRAS account for about $85 \%$ of all RAS mutations in human tumors; NRAS for about 15\%; and HRAS for less than $1 \% .{ }^{6}$ RAS mutations are useful markers for predicting responses to anti-epidermal growth factor receptor (EGFR) monoclonal antibodies (like cetuximab or panitumumab), especially in metastatic colorectal cancers (CRC). Approximately 30-50\% of CRCs have KRAS mutations and currently, the KRAS status is known to be a selective marker of predicting response to anti-EGFR antibodies. The tumors of patients with metastatic CRC are now investigated routinely for KRAS mutations before receiving cetuximab or panitumumab. ${ }^{5,8-10}$ However previous studies have shown that, in more than half (up to $65 \%$ ) of the patients with wild type KRAS gene, CRC still fails to respond to anti-EGFR therapy. This suggests the involvement of mutations at other locations of gene or other genes that act downstream of EGFR in the RAS/ $\mathrm{RAF} / \mathrm{MEK} / \mathrm{ERK}$ pathway. ${ }^{11}$ Regarding this point, it is recommended to test for KRAS mutation as the first step and then in wild type KRAS, analysis for BRAF mutation should be the second step. In the presence of wild type BRAF, NRAS mutation analysis should be the third step, and PIK3CA exon 20 should be analysed as the fourth and final step. ${ }^{12}$ KRAS and BRAF are mutually exclusive. Many studies have shown that the NRAS mutation affects the efficacy of anti-EGFR antibodies and is

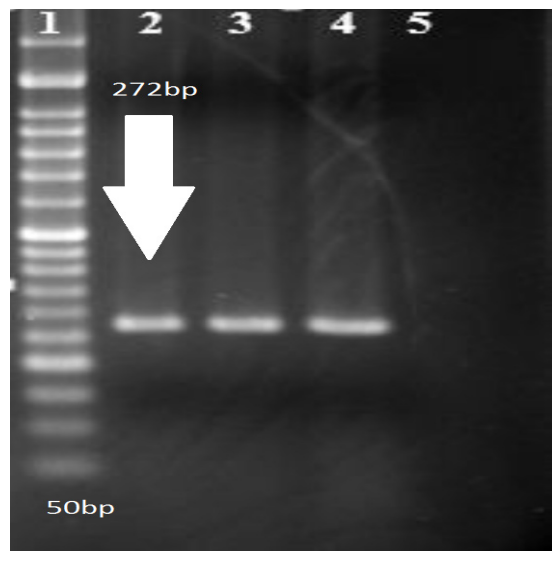

1: Ladder 2, 3, and 4: Patients 5: Negative control

Fig.2: NRAS codon 61 gel picture and sequencing result

significantly associated with a low response rate to these drugs. ${ }^{12,13}$ Also some studies have shown significant association of NRAS mutation with specific locations of colon involvements and distant metastasis in CRC. ${ }^{13-15}$

To the best of our knowledge only two published studies have been reported from Iran about the frequency of NRAS in KRAS and BRAF mutation negative CRCs. ${ }^{17,18}$ In this study, we want to identify NRAS mutations rate and spectrum (at codons 12, 13, and 61) in 52 KRAS and BRAF wild type during 5 years (2011-2015) in the hospitals affiliated to Shiraz University of Medical Sciences as the largest referral center in south of Iran.

\section{MATERIALS AND METHODS}

During 5 years from June 2011 to June 2015, all wild type KRAS and BRAF CRCs who were referred to hospitals affiliated to Shiraz University of Medical Sciences and had enough tissue for molecular studies, were included in this study. Recurrent and post chemotherapy cases were excluded from the study. It means that none of our cases had been treated. In the meanwhile all of them were sporadic cases of CRC with no case of Lynch Syndrome. Hematoxylin and Eosin slides were reviewed and proper slides with minimum necrosis and maximum well preserved tumor cells (at least $50 \%$ of tumor cells) were selected. NRAS codon 12, 13, and 61 mutations were investigated by using polymerase chain reaction (PCR) and direct sequencing (Sanger). DNA extraction and purification of each case was performed from paraf- 


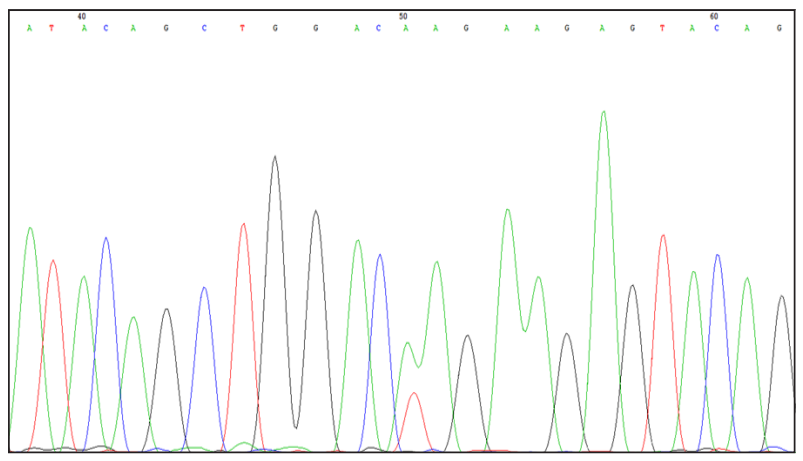

Fig.3: Diagram of the DNA sequencing shows Forward sequence, codon 16: Normal: CAA, Mutant: CTA (Q61L)

fin embedded formalin fixed (PEFF) tissue using Qiagen extraction and purification kit. Then PCR amplification of DNA was done (figures 1 and 2) followed by DNA sequencing by Sanger method (figure 3).

\section{RESULTS}

During these 5 years we collected 52 cases of CRCs with wild type KRAS and BRAF, which were included in this study. Age range of the patients was 26 to 85, with mean age of $57.92 \pm 13.93$ years. There were 29 male and 23 female patients in this study population. Among these cases 15 CRCs were in sigmoid colon, 14 in ascending colon, 13 in rectum, 5 in descending colon, 4 in rectosigmoid, and 1 in transverse colon. Most of the cases were well differentiated (69\%), T3 (50\%), and polypoid (40\%).

Among these 52 KRAS and BRAF wild type patients with CRC, there were 3 (5.7\%) patients with mutations in NRAS gene. The remaining 49 patients showed wild type NRAS.

Of the three mutant individuals, one of the mutations was located in codon 12, leading to the substitution of Guanine by Thymidine $(35 \mathrm{G}>\mathrm{T})$ (normal sequence of the codon $12=$ GGT, replaced by GTT), resulting in amino acid substitution of glycine to valine.

In both of the other two mutant individuals, the mutations were detected in codon 61 , one of which led to the substitution of cytosine by adenine $(181 \mathrm{C}>\mathrm{A})$ (normal sequence of the codon $61=\mathrm{CAA}$, replaced by AAA), resulting in amino acid substitution of glutamine to lysine. The second one resulted the substitution of adenine by thymidine $(182 \mathrm{~A}>\mathrm{T})$ (normal sequence of the codon $61=\mathrm{CAA}$, replaced by CTA), resulting in amino acid substitution of glutamine to leucine. No mutation in codon 13 was detected.

All the three mutant patients were women with age $\geq 40$ years (mean: 50.33). All the three cases were stage IV, and well differentiated. Two of the mutant cases were located in sigmoid colon, and the other one in rectum.

\section{DISCUSSION}

$\mathrm{CRC}$ is one of the common cancers in human being with growing incidence in eastern countries such as Iran. ${ }^{3}$ There are important molecular features in this cancer such as mutations in RAS family (KRAS, NRAS, and HRAS). Among the RAS family, mutations in KRAS accounts for about $85 \%$ of all RAS mutations in human tumors, NRAS for about $15 \%$, and HRAS for less than $1 \% 0^{3-7}$

NRAS is identical to KRAS in the first 85 amino acids. ${ }^{19}$ However, unlike KRAS, NRAS is not activated by specific cytokines or growth factors ${ }^{20}{ }^{20}$ so mutant NRAS protects CRC cells from stress-induced apoptosis. ${ }^{21}$ These mutations of NRAS mostly occur in codons 12 and 13 (exon 2), 61 (exon 3), 117, and 146 (exon 4). There is a low chance for cancer cells with mutated forms of KRAS and NRAS genes to respond to treatment by antiEFGER (epidermal growth factor) monoclonal antibodies, and cancer and metastasis may continue to progress in spite of treatment. Examples of such drugs are cetuximab and panitumumab. ${ }^{17}$

There are reports about worse prognosis of CRCs with NRAS mutations. ${ }^{22}$ Early identification of mutations should be performed to guide patients with metastatic CRC toward targeted therapies. Many studies have proved the impact of NRAS genes activating mutations, on prognosis and resistance (low response) to anti-EGFR therapy. ${ }^{13,14,23-27}$ In CRCs with wild type KRAS gene, analysis of NRAS mutations is considered necessary. ${ }^{28}$

As indicated by the result of our study, among 52 KRAS and BRAF wild type patients with CRC, there were $3(5.7 \%)$ patients with mutations in NRAS gene. No NRAS mutation was detected in the remaining 49 patients (wild type NRAS gene).

In concordance with our results, in previous studies, NRAS mutations have been also rarely detected. The overall frequency of NRAS mutations in CRC has ranged between 2-7. 4\% (table 1 and 2). As shown in the table, the difference in frequencies is secondary to 
Table 1: Reported frequencies of NRAS mutations in different countries of Asia, America, and Europe

\begin{tabular}{|c|c|c|c|c|c|c|c|}
\hline Author & Country & Year & Method & $\begin{array}{l}\text { Sample } \\
\text { size }\end{array}$ & KRAS and BRAF & $\begin{array}{c}\text { NRAS } \\
\text { mutation }\end{array}$ & $\begin{array}{c}\text { Most } \\
\text { common } \\
\text { Mutation }\end{array}$ \\
\hline Al Shamsi $\mathrm{HO}^{27}$ & $\begin{array}{l}\text { USA (Arab } \\
\text { Population) }\end{array}$ & 2016 & PCR-NGS* & 99 & Wild & $4 \%$ & $\mathrm{NR} * *$ \\
\hline Chang Yo- Yao 21 & Taiwan & 2016 & PCR-Sequencing & 1519 & Wild and mutant & $4.3 \%$ & 61 \\
\hline Shen $Y^{16}$ & China & 2013 & PCR-Sequencing & 621 & Wild and mutant & $4.19 \%$ & 61 \\
\hline Zhang $\mathrm{J}^{31}$ & China & 2015 & PCR-Sequencing & 1110 & Wild and mutant & $3.9 \%$ & 12 \\
\hline Bando $\mathrm{H}^{30}$ & Japan & 2013 & PCR-Sequencing & 82 & Wild & $2.4 \%$ & 12 \\
\hline Soeda $\mathrm{H}^{32}$ & Japan & 2014 & PCR-Sequencing & 43 & Wild & $4.7 \%$ & 12 \\
\hline Bagadie SP ${ }^{29}$ & India & 2012 & PCR-Sequencing & 100 & NR & $2 \%$ & NR \\
\hline Palomba G ${ }^{33}$ & Italy & 2016 & PCR-Sequencing & 1288 & Wild & $4.1 \%$ & NR \\
\hline Modest DP ${ }^{26}$ & Germany & 2016 & PCR-Sequencing & 1239 & NR & $3.1 \%$ & NR \\
\hline Bulschun $\mathrm{K}^{36}$ & Germany & 2011 & PCR-Sequencing & 57 & $\begin{array}{c}\text { KRAS: Mutant and } \\
\text { wild } \\
\text { BRAF:NR }\end{array}$ & $3.5 \%$ & 61 \\
\hline Scalfani $F^{34}$ & Europe & 2014 & PCR-Sequencing & 90 & Wild type & $4.4 \%$ & 3 \\
\hline Douillard NY 23 & Europe & 2013 & PCR-Sequencing & 641 & $\begin{array}{c}\text { KRAS: Mutant and } \\
\text { wild } \\
\text { BRAF:NR }\end{array}$ & $7.4 \%$ & 61 \\
\hline Peeters $\mathrm{M}^{25}$ & USA, Europe & 2013 & PCR-NGS & 282 & $\begin{array}{c}\text { Kras: Mutant and } \\
\text { wild } \\
\text { BRAF: Wild }\end{array}$ & $5 \%$ & NR \\
\hline Morris VK ${ }^{35}$ & USA & 2014 & PCR-Sequencing & 484 & NR & $4.1 \%$ & 61 \\
\hline Vaughn $\mathrm{CP}^{37}$ & USA & 2011 & PCR-Sequencing & 513 & $\begin{array}{c}\text { Kras: Mutant and } \\
\text { wild } \\
\text { BRAF: Wild }\end{array}$ & $5.06 \%$ & 61 \\
\hline Irahara $\mathrm{N}^{14}$ & USA & 2010 & PCR & 225 & Wild & $2.2 \%$ & 12 \\
\hline Russo A ${ }^{15}$ & USA & 2014 & $\begin{array}{c}\text { SNAPshot } \\
\text { Multiplex system }\end{array}$ & 222 & Wild & $4.05 \%$ & 12 \\
\hline De Rook ${ }^{13}$ & Europe & 2010 & PCR & 644 & Wild & $2.6 \%$ & 61 \\
\hline
\end{tabular}

(NR: Not reported, NGS: nest generation sequencing)

Table 2: Reported studies about NRAS mutations from Iran

\begin{tabular}{|c|c|c|c|c|c|c|c|}
\hline Author & Country & Year & Method & $\begin{array}{l}\text { Sample } \\
\text { size }\end{array}$ & KRAS and BRAF & $\begin{array}{c}\text { NRAS } \\
\text { mutation }\end{array}$ & $\begin{array}{l}\text { Most common } \\
\text { mutation }\end{array}$ \\
\hline Naseri et al. ${ }^{17}$ & Iran & 2016 & Real time-sequencing & 50 & Not Reported & $2 \%$ & $\begin{array}{l}\text { Codon } 146 \\
\text { (exon3): } \\
(436 \mathrm{G}>\mathrm{A}) \\
\text { Ala to } \mathrm{Thr}\end{array}$ \\
\hline Payande et al. ${ }^{18}$ & Iran & 2016 & Allele specific-sequencing & 83 & Not Reported & $4.3 \%$ & Not reported \\
\hline Current Study & Iran & 2016 & PCR-Sequencing & 50 & Wild type & $5.7 \%$ & $\begin{array}{c}\text { Codon } 61 \\
181 \mathrm{C}>\mathrm{A} \text { and } \\
182 \mathrm{~A}>\mathrm{T}\end{array}$ \\
\hline
\end{tabular}

ethnic variations. Some studies have reported the incidence of NRAS in wild type KRAS and BRAF, while some others searched NRAS mutation frequency in both mutant and wild type KRAS and BRAF CRCs. In wild type KRAS and BRAF, NRAS mutation rate has been re- ported to be between $2.4 \%$ to $4.7 \% .{ }^{29-36}$ Only two studies from Iran previously showed NRAS mutation frequencies of 0 and $2 \%$ (table 2). ${ }^{17,18}$ Our results are very close to the reports from the other parts of the world but we report a little higher mutation rate in wild type KRAS 
and BRAF CRCs compared with the previous reports i.e. $5.7 \%$ versus $2.2 \%$ to $4.7 \%$. This difference could probably be due to differences in geographic region as well as ethnic population. ${ }^{13-15,27,30,32-34}$

Our study showed no statistically significant associations, between NRAS mutations and clinicopathological features such as age, sex, tumor site, stage, and tumor histological grade. Most of the previous studies have also reported the same results with no significant difference between factors such as age, sex, tumor location, stage of disease, and tumor grade with NRAS mutations $(p>0.05) \cdot{ }^{27-29}$

\section{CONCLUSION}

Iranian patients with $\mathrm{CRC}$ can benefit from routine mutational status analysis, before starting the treatment with anti-EGFR antibody drugs. Therefore NRAS mutation although is rare, should be definitely investigated in wild type KRAS and BRAF, before treatment, because according to our findings, about $5.7 \%$ of the patients with CRCs and wild type KRAS and BRAF, would have NRAS mutation, which causes negative interference with anti-EGFR treatment.

\section{ACKNOWLEDGEMENTS}

This thesis has been performed by the financial support of Shiraz University of Medical Sciences (project No-8489)

\section{ETHICAL APPROVAL}

There is nothing to be declared.

\section{CONFLICT OF INTEREST}

The authors declare no conflict of interest related to this work.

\section{REFERENCES}

1. Odze R, Goldblum JR. Surgical pathology of the GI Tract, Liver, Biliary Tract, and Pancreas. 3rd ed. Elsevier: Saunders; 2015;1,Part I. Sec 4. Epithelial Neoplasms of the Gastrointestinal Tract; p:737-78.

2. Colussi D, Brandi G, Bazzoli F, Ricciardiello L. Molecular pathways involved in colorectal cancer: implications for disease behavior and prevention. Int J Mol Sci 2013;14:16365-85. doi: 10.3390/ijms140816365.

3. Geramizadeh B. Molecular biomarkers of colorectal cancer: A Review of Published Articles from Iran. Ann colorectal Res 2015;3:e30100.
4. Bosman F, Yan P. Molecular pathology of colorectal cancer. Pol J Pathol 2014;65:257-66. doi: 10.5114/ pjp.2014.48094.

5. Diaz-Flores E, Shannon K. Targeting oncogenic Ras. Genes Dev 2007;21:1989-92. doi: 10.1101/gad.1587907.

6. Omidifar N, Geramizadeh B, Mirzai M. K-ras Mutation in Colorectal Cancer, A Report from Southern Iran. Iran J Med Sci 2015;40:454-60.

7. Javadi F, Geramizadeh B, Mirzai M. BRAF Gene Mutation Analysis in Colorectal Cancer in South of Iran. Ann Colorectal Res 2014;2:e19917. doi:10.17795/acr-19917.

8. Downward J. Targeting RAS signaling pathways in cancer therapy. Nat Rev Cancer 2003;3:11-22. doi:10.1038/nrc969.

9. Van Cutsem E, Köhne CH, Hitre E, Zaluski J, Chang Chien CR, Makhson A, et al. Cetuximab and chemotherapy as initial treatment for metastatic colorectal cancer. $N$ Engl J Med 2009;360:1408-17. doi: 10.1056/NEJMoa0805019.

10. Lièvre A, Bachet JB, Boige V, Cayre A, Le Corre D, Buc E, et al. KRAS mutations as an independent prognostic factor in patients with advanced colorectal cancer treated with cetuximab. J Clin Oncol 2008;26:374-9. doi: 10.1200/JCO.2007.12.5906.

11. De Roock W, Piessevaux H, De Schutter J, Janssens M, De Hertogh G, Personeni N, et al. KRAS wild-type state predicts survival and is associated to early radiological response in metastatic colorectal cancer treated with cetuximab. Ann Oncol 2008;19:508-15. doi: 10.1093/annonc/mdm496.

12. Allegra CJ, Jessup JM, Somerfield MR, Hamilton SR, Hammond EH, Hayes DF, et al. American Society of Clinical Oncology provisional clinical opinion: Testing for KRAS gene mutations in patients with metastatic colorectal carcinoma to predict response to anti-epidermal growth factor receptor monoclonal antibody therapy. J Clin Oncol 2009;27:2091-6. doi: 10.1200/ JCO.2009.21.9170.

13. De Roock W, Claes B, Bernasconi D, De Schutter J, Biesmans B, Fountzilas G, et al. Effects of KRAS, BRAF, NRAS, and PIK3CA mutations on the efficacy of cetuximab plus chemotherapy in chemotherapy-refractory metastatic colorectal cancer: a retrospective consortium analysis. Lancet Oncol 2010;11:753-62. doi: 10.1016/ S1470-2045(10)70130-3

14. Irahara N, Baba $\mathrm{Y}$, Nosho $\mathrm{K}$, Shima K, Yan L, DiasSantagata D, et al. NRAS mutations are rare in colorectal cancer. Diagn Mol Pathol 2010;19:157-63. doi: 10.1097/ PDM.0b013e3181c93fd1.

15. Russo AL, Borger DR, Szymonifka J, Ryan DP, Wo JY, Blaszkowsky LS, et al. Mutational analysis and clinical correlation of metastatic colorectal cancer. Cancer 2014;120:1482-90. doi: 10.1002/cncr.28599.

16. Shen Y, Wang J, Han X, Yang H, Wang S, Lin D, et al. Effectors of epidermal growth factor receptor pathway: the genetic profiling of KRAS, BRAF, PIK3CA, NRAS 
mutations in colorectal cancer characteristics and personalized medicine. PLoS One 2013;8:e81628. doi: 10.1371/ journal.pone.0081628.

17. Naseri M, Sebzari A, Haghighi F, Hajipoor F, Emadian Razavi F. Frequency of K-RAS and N-RAS Gene Mutations in Colorectal Cancers in Southeastern Iran. Asian Pac J Cancer Prev 2016;17:4511-15.

18. Payandeh M, Shazad B, Sadeghi M, Shahbazi M. Correlation between RAS Test Results and Prognosis of Metastatic Colorectal Cancer Patients: a Report from Western Iran. Asian Pac J Cancer Prev 2016;17:1729-32. doi: 10.7314/APJCP.2016.17.4.1729.

19. Malumbres M, Barbacid M. RAS oncogenes: The first 30 years. Nat Rev Cancer 2003;3:459-65. doi:10.1038/ nrc1097.

20. Ehrhardt A, David MD, Ehrhardt GR, Schrader JW. Distinct mechanisms determine the patterns of differential activation of H-Ras, N-Ras, K-Ras 4B, and M-Ras by receptors for growth factors or antigen. Mol and cell Biol 2004;24:6311-23. doi: 10.1128/MCB.24.14.63116323.2004 .

21. Chang YY, Lin PC, Lin HH, Lin JK, Chen WS, Jiang JK, et al. Mutation spectra of RAS gene family in colorectal cancer. Am J Surg 2016;212:537-44. doi: 10.1016/j.amjsurg.2016.02.013.

22. Wang Y, Velho S, Vakiani E, Peng S, Bass AJ, Chu GC, et al. Mutant N-RAS protects colorectal cancer cells from stress-induced apoptosis and contributes to cancer development and progression. Cancer Discov 2013;3:294-307. doi: 10.1158/2159-8290.CD-12-0198.

23. Douillard JY, Oliner KS, Siena S, Tabernero J, Burkes $\mathrm{R}$, Barugel M, et al. Panitumumab-FOLFOX4 treatment and RAS mutations in colorectal cancer. $N$ Eng $J$ Med 2013;369:1023-34. doi: 10.1056/NEJMoa1305275.

24. Di Bartolomeo M, Pietrantonio F, Perrone F, Dotti KF, Lampis A, Bertan C, et al. Lack of KRAS, NRAS, BRAF and TP53 mutations improves outcome of elderly metastatic colorectal cancer patients treated with cetuximab, oxaliplatin and UFT. Target Oncol 2014;9:155-62. doi: 10.1007/s11523-013-0283-8.

25. Peeters M, Oliner KS, Parker A, Siena S, Van Cutsem E, Huang $\mathrm{J}$, et al. Massively parallel tumor multigene sequencing to evaluate response to panitumumab in a randomized phase III study of metastatic colorectal cancer. Clin Cancer Res 2013;19:1902-12. doi: 10.1158/10780432.

26. Modest DP, Ricard I, Heinemann V, Hegewisch-Becker $\mathrm{S}$, Schmiegel W, Porschen R, et al. Outcome according to KRAS-, NRAS-and BRAF-mutation as well as KRAS mutation variants: pooled analysis of five randomized trials in metastatic colorectal cancer by the AIO colorectal cancer study group. Ann Oncol 2016;27:1746-53. doi: 10.1093/annonc/mdw261.

27. Al-Shamsi HO, Jones J, Fahmawi Y, Dahbour I, Tabash A, Abdel-Wahab R, et al. Molecular spectrum of KRAS, NRAS, BRAF, PIK3CA, TP53, and APC somatic gene mutations in Arab patients with colorectal cancer: determination of frequency and distribution pattern. $J$ Gastrointest Oncol 2016;7:882. doi: 10.21037/jgo.2016.11.02.

28. Er TK, Chen CC, Bujanda L, Herreros-Villanueva M. Current approaches for predicting a lack of response to anti-EGFR therapy in KRAS wild-type patients. Bio Med Res Int 2014;2014:591867. doi: 10.1155/2014/591867.

29. Bagadi SB, Sanghvi M, Nair SB, Das BR. Combined mutational analysis of KRAS, NRAS and BRAF genes in Indian patients with colorectal carcinoma. Int J Biol Markers 2012;27:27-33. doi: 10.5301/JBM.2012.9108.

30. Bando H, Yoshino T, Shinozaki E, Nishina T, Yamazaki $\mathrm{K}$, Yamaguchi K, et al. Simultaneous identification of 36 mutations in KRAS codons 61and 146, BRAF, NRAS, and PIK3CA in a single reaction by multiplex assay kit. BMC Cancer 2013;13:405. doi: 10.1186/1471-2407-13405.

31. Zhang J, Zheng J, Yang Y, Lu J, Gao J, Lu T, et al. Molecular spectrum of KRAS, NRAS, BRAF and PIK3CA mutations in Chinese colorectal cancer patients: analysis of 1,110 cases. Sci Rep 2015;5:18678. doi:10.1038/ srep18678.

32. Soeda $\mathrm{H}$, Shimodaira $\mathrm{H}$, Gamoh $\mathrm{M}$, Ando $\mathrm{H}$, Isobe $\mathrm{H}$, Suto T, et al. Phase II trial of cetuximab plus irinotecan for oxaliplatin-and irinotecan-based chemotherapy-refractory patients with advanced and/or metastatic colorectal cancer: evaluation of efficacy and safety based on KRAS mutation status (T-CORE0801). Oncology 2014;87:7-20. doi: $10.1159 / 000360989$.

33. Palomba G, Doneddu V, Cossu A, Paliogiannis P, Manca A, Casula M, et al. Prognostic impact of KRAS, NRAS, BRAF and PIK3ca mutations in primary colorectal carcinomas: a population-based study. J Transl Med 2016;14:292. doi: 10.1186/s12967-016-1053-z.

34. Sclafani F, Gonzalez D, Cunningham D, Wilson SH, Peckitt C, Giralt J, et al. RAS mutations and cetuximab in locally advanced rectal cancer: results of the EXPERTC trial. Eur J Cancer 2014;50:1430-6. doi: 10.1016/j. ejca.2014.02.002.

35. Morris VK, San Lucas FA, Overman MJ, Eng C, Morelli MP, Jiang ZQ, et al. Clinicopathologic characteristics and gene expression analyses of non-KRAS 12/13, RAS-mutated metastatic colorectal cancer. Ann Oncol 2014;25:2008-14. doi: 10.1093/annonc/mdu252.

36. Balschun K, Haag J, Wenke AK, von Schönfels W, Schwarz NT, Röcken C. KRAS, NRAS, PIK3CA exon 20 , and BRAF genotypes in synchronous and metachronous primary colorectal cancers: Diagnostic and therapeutic implications. J Mol Diagn 2011;13:436-45. doi: 10.1016/j.jmoldx.2011.03.002.

37. Vaughn CP, ZoBell SD, Furtado LV, Baker CL, Samowitz WS. Frequency of KRAS, BRAF, and NRAS mutations in colorectal cancer. Genes Chromosomes Cancer 2011;50:307-12. doi: 10.1002/gcc.20854. 